\title{
ANALISA KEBUTUHAN TENAGA REKAM MEDIS BERDASARKAN BEBAN KERJA DENGAN METODE WISN DI BAGIAN PENDAFTARAN RUMAH SAKIT UMUM HAJI MEDAN TAHUN 2018
}

\author{
${ }^{1}$ Suheri Parulian Gultom, ${ }^{2}$ Afrizal Sihotang \\ 1. Dosen APIKES Imelda, Jalan Bilal Nomor 52 Medan; ${ }^{2}$ Alumni APIKES Imelda
}

Email: ${ }^{1 .}$ suheriparuliangultom@gmail.com

\begin{abstract}
ABSTRAK
Pelayanan di bagian pendaftaran bersifat administratif yaitu pelayanan dalam mengidentifikasi pasien. Oleh karena itu harus diupayakan pelayanan yang cepat agar pasien tidak lama menunggu. Salah satu kendala di pendaftaran adalah jumlah tenaga yang terbatas. Berdasarkan survey pendahuluan rata-rata kunjungan pasien rawat jalan 4250 kunjungan dan rawat inap 2048 kunjungan. Dimana rat-rata pasien perhari sebanyak 209orang. Tujuan penelitian ini untuk mengetahui perkiraan kebutuhan tenaga rekam medis berdasarkan beban kerja dengan menggunakan metode WISN di bagian pendaftran Rumah Sakit Umum Haji tahun 2018. Jenis penelitian diskriptif dengan pendekatan cross sectional dengan populasi kunjungan pasien rawat jalan dan rawat inap pada bulan Maret-Mei 2018 sebanyak 3149 pasien. Hasil penelitian dengan menggunakan metode WISN perkiraan tenaga rekam medis di bagian pendaftaran yang dibutuhkan sebanyak 1 petugas, sedangkan terjadinya antrian dikarenakan pasien yang berkunjung datang disaat jam yang bersamaan. Antrian juga terjadi karena DRM yang dicari tidak ditemukan di rak filing dan pasien tidak membawa KIB.Terdapat kekurangan tenaga rekam medis di bagian pendaftaran di Rumah Sakit Umum Haji karena dari hasil perhitungan dibutuhkan tambahan 1 orang dan saat ini hanya ada 2 orang tenaga rekam medis .
\end{abstract}

Kata Kunci : : Tenaga Rekam Medis, Pendaftaran, Beban Kerja

\section{PENDAHULUAN}

Rumah sakit adalah suatu bagian menyeluruh dari organisasi sosial dan medis berfungsi memberikan pelayanan kesehatan yang lengkap kepada masyarakat, baik kuratif maupun rehabilitatif, dimana menjangkau pelayanan keluarga dan lingkungan. Rumah sakit merupakan sebuah institusi pelayanan kesehatan profesional yang pelayanannya dilakukan oleh dokter, perawat, dan tenaga ahli kesehatan lainnya. Pelayanan rumah sakit merupakan bagian yang tidak terpisahkan dari sistem pelayanan kesehatan pada umumnya, yang memerlukan penanganan dan perhatian yang seksama (WHO, 2009).

Menurut Undang-Undang RI No. 44 Tahun 2009, rumah sakit adalah institusi pelayanan kesehatan bagi masyarakat dengan karakteristik tersendiri yang dipengaruhi oleh perkembangan ilmu pengetahuan kesehatan, kemajuan teknologi dan kehidupan sosial ekonomi masyarakat yang harus tetap mampu meningkatkan pelayanan yang lebih bermutu dan terjangkau oleh masyarakat agar terwujud derajat kesehatan yang setinggi-tingginya. Rumah Sakit adalah institusi pelayanan kesehatan yang menyelenggarakan pelayanan kesehatan 
perorangan secara paripurna yang menyediakan pelayanan rawat inap, rawat jalan dan gawat darurat.

Dalam penjelasan Pasal 46 ayat (1) Undang-Undang Praktik Kedokteran, yang dimaksud dengan rekam medis adalah berkas yang berisi catatan dan dokumen tentang identitas pasien, pemeriksaan, pengobatan, tindakan dan pelayanan lain yang telah diberikan kepada pasien (UU No. 29 Tahun 2004.

Tujuan rekam medis adalah untuk menunjang tercapainya tertib administrasi dalam rangka upaya peningkatan pelayanan kesehatan di rumah sakit. Tanpa didukung suatu sistem pengelolaan rekam medis yang baik dan benar, mustahil tertib administrasi rumah sakit akan berhasil sebagaimana yang diharapkan (Depkes, 2008).

Tempat pendaftaran pasien atau yang sering dikenal sebagai loket pendaftaran pasien merupakan bagian terpenting dari pelayanan kesehatan di rumah sakit, yang memberi pelayanan pertama kali kepada pasien serta pencatatan identitas pasien. Tempat pendaftaran dibagi menjadi tiga bagian yaitu: Tempat pendaftaran pasien rawat jalan (TPPRJ), Tempat pendaftaran pasien rawat inap (TPPRI) dan Tempat pendaftaran pasien gawat darurat (TPPGD). Tempat pendaftaran pasien merupakan tempat pelayanan pasien pertama kali sehingga perlu ditugaskan seorang petugas yang ramah, cepat, teliti dan rapi. (KARS, 2012).

Sarana pelayanan kesehatan terutama rumah sakit dalam menghadapi era globalisasi berupaya meningkatkan kualitas akan jasa yang ditawarkan kepada masyarakat. Hal ini disebabkan karena kualitas jasa dapat digunakan sebagai alat untuk mencapai keunggulan kompetitif. Implementasi kualitas jasa yang dilakukan oleh sarana pelayanan kesehatan dengan cara memberikan pelayanan terbaik bagi konsumen dengan tujuan menciptakan kepuasan pasien (Bustami, 2011).

Bagian pendaftaran merupakan sub unit di instalasi rekam medis suatu rumah sakit dimana berfungsi dalam pengumpulan data melalui identitas pasien.Untuk melaksanakan pekerjaan pendaftaran di unit rekam medis rumah sakit harus memiliki tenaga rekam medis yang memenuhi standar dilihat dari kuantitas maupun kualitasnya. Tenaga rekam medis di bagian pendaftaran harus memiliki kompetensi yang baik dan mumpuni dalam melakukan pelayanan rekam medis. Tenaga rekam medis harus memiliki pengetahuan, sikap dan keterampilan dalam melakukan pekerjaannya sehingga pelayanan rekam medis lebih bermutu dan dapat dipertanggung jawabkan (Budi, 2011).

Perencanaan sumber daya manusia merupakan fungsi utama yang harus dilaksanakan oleh setiap organisasi serta harus menjadi fokus perhatian sehingga langkah-langkah yang diambil oleh manajemen menjadi tepat guna, lebih menjamin bahwa di dalam organisasi tersedia tenaga kesehatan untuk menduduki jabatan dan pekerjaan yang tepat dalam rangka mencapai suatu tujuan dan berbagai sasaran yang telah ditetapkan. Salah satu bentuk perencanaan sumber daya manusia kesehatan adalah perencanaan tenaga rekam medis (Kemenkes, 2017).

Menurut Undang-Undang No 36 Tahun 2014, Perekam medis dan informasi kesehatan merupakan salah satu tenaga kesehatan yang termasuk dalam kelompok tenaga keteknisian medis. Tugas dari perekam medis dan informasi kesehatan yaitu mengelola data pasien menjadi informasi kesehatan yang berguna bagi pengambilan keputusan. Pengelolaan rekam medis yang baik membutuhkan tenaga kerja yang kompeten dalam bidang rekam medis dilihat dari segi kualitas maupun kuantitas. Kualitas tenaga kerja meliputi 
pengetahuan, keterampilan dan tingkat pendidikan, sedangkan kuantitas adalah jumlah tenaga kerja yang ada harus sesuai dengan beban kerja.

Beban kerja sangat memengaruhi efisiensi, efektivitas dan produktifitas tenaga kerja. Sehingga perlu adanya kesesuaian antara jumlah tenaga kerja dengan beban kerja di suatu unit pelayanan. Salah satu metode untuk mengetahui kebutuhan tenaga kerja yaitu dengan menggunakan metode WISN dimana metode tersebut dapat menunjukkan besarnya kebutuhan tenaga pada sarana kesehatan berdasarkan beban kerja, sehingga lokasi atau relokasi akan lebih mudah dan rasional (Nuraini, 2010).

Menurut Astiena

(2015), menyebutkan bahwa beban kerja tenaga kesehatan adalah banyaknya pekerjaan yang harus diselesaikan oleh tenaga kesehatan profesional dalam satu tahun dalam satu sarana pelayanan kesehatan. Beban kerja pada satu unit pada dasarnya merupakan keseimbangan antara kuantitas dan kualitas pekerjaan yang dituntut dari karyawan dengan jumlah tenaga yang ada dalam suatu unit tersebut. Beban kerja juga mempertimbangkan standar jumlah tenaga menurut profesi tersebut, standar kualifikasi dan standar evaluasi pekerjaan. Jadi, tinggi rendahnya beban kerja tidak hanya tergantung pada jumlah tenaga yang tersedia, namun tergantung juga dengan kualifikasi tenaga kesehatan tersebut. Beban kerja bisa menjadi tinggi apabila kompetensi tenaga kesehatan lebih rendah dari kualifikasi yang disyaratkan, begitu juga sebaliknya.

Analisis terhadap beban kerja tenaga rekam medis sangat diperlukan dalam rangka meningkatkan pelayanan rekam medis di suatu rumah sakit. Hal ini bertujuan agar dapat diketahui beban kerja mana yang perlu di efisiensikan. Selain itu, dengan adanya analisis atau pengukuran beban kerja, dapat dilakukan pengambilan keputusan yang berbasis bukti ilmiah. Melihat besarnya peranan rekam medis dalam pelayanan rumah sakit, maka sudah saatnya perlu mendapatkan perhatian yang tinggi terkait hal-hal apa saja yang menunjang demi peningkatan kualitas terbaik di instalasi rekam medis (PPSDM, 2017).

Rumah Sakit Haji Medan memiliki 2 tempat pendaftaran pasien, yaitu rawat jalan (TPPRJ) dan tempat pendaftran pasien rawat inap (TPPRI). Jumlah tenaga rekam medis di bagian pendaftaran adalah 2 orang dari jumlah seluruh petugas 6 orang. Berdasarkan jadwal dinas, diketahui bahwa tenaga rekam medis yang terlambat masuk kerja pada bulan April 2018 rata-rata keterlambatan adalah 5 hari. Diketahui juga bahwa dari rekapitulasi laporan kunjungan pasien pada bulan Januari sampai dengan April 2018 berjumlah 6298 , terdiri dari pasien rawat jalan 4250 dan rawat inap 2048.

Berdasarkan survey pendahuluan dengan melakukan wawancara pada tenaga rekam medis di Rumah Sakit Haji Medan, diketahui bahwa terdapat beban kerja yang dirasakan tenaga pelaksana diantaranya, kejenuhan, kelelahan dan tingkat stress yang cukup tinggi baik di bagian pendaftaran maupun di bagian pengolahan rekam medis, karena mengingat pekerjaan yang mereka lakukan adalah pekerjaan yang serupa dan berurutan dari waktu ke waktu. Keadaan lainnya yaitu kejadian status rekam medis tidak ditemukan, hal ini membutuhkan waktu untuk proses pencarian pada saat pelayanan. Keadaan tersebut memicu antrian yang menjadi semakin panjang. Selain itu terdapat tenaga pelaporan yang turut membantu untuk melayani pendaftaran pasien rawat jalan selama satu hari penuh. Serta petugas pendaftaran pasien memiliki tugas untuk melakukan pemberian informasi kepada pasien.

Berdasarkan hasil perhitungan waktu tunggu 30 pasien di bagian 
pendaftaran di dapatkan rata-rata waktu 12 menit 25 detik untuk pasien rawat jalan dan 20 menit 16 detik untuk pasien rawat inap. Dimana untuk standar pelayanan minimal waktu penyediaan rekam medis rawat jalan $\leq 10$ menit dan rawat inap $\leq 15$ menit 2008).

Berdasarkan observasi yang dilakukan peneliti, diketahui juga bahwa tenaga rekam medis di bagian pendaftaran mempunyai tugas dalam pengumpulan data pasien sesuai identitas pasien, pemberian nama pasien, pemberian nomor rekam medis, pencatatan pada buku register dan komputer, pembuatan Kartu Indeks Utama Pasien (KIUP), pembuatan tracer, buku peminjaman rekam medis, pengambilan berkas rekam medis dari rak penyimpanan untuk disediakan pada pasien yang berobat ke rumah sakit.

Berdasarkan uraian dari latar belakang di atas, maka penulis tertarik melakukan penelitian tentang "Analisa Kebutuhan Tenaga Rekam Medis Berdasarkan Beban Kerja Dengan Metode WISN di Bagian Pendaftran Rumah Sakit Umum Haji Medan Tahun 2018".

\section{METODE}

Jenis penelitian yang digunakan adalah penelitian deskriptif dengan menggunakan pendekatan cross sectional yang bertujuan untuk mengetahui bagaimana kebutuhan tenaga rekam medis berdasarkan beban kerja dengan metode WISN di bagian pendaftaran Rumah Sakit Umum Haji MedanTahun 2018. Lokasi penelitian dilakukan di Rumah Sakit Umum Haji Medan. Adapun alasan pemilihan lokasi penelitian, karena adanya masalah tentang kebutuhan tenaga rekam medis di bagian pendaftaran dan belum pernah dilakukan penelitian sebelumnya. Penelitian ini dilakukan pada bulan September 2018 sampai dengan
Desember 2018. Populasi dari penelitian ini adalah kunjungan pasien rawat jalan dan rawat inap pada bulan Maret sampai dengan Mei 2018 dan 2 orang tenaga rekam medis yang melakukan kegiatan di bagian pendaftaran pasien dimana seluruh populasi dijadikan sampel penelitian.

\section{Variabel dan Definisi Operasional}

1. Waktu kerja tersedia adalah waktu yang tersedia bagi tenaga rekam medis di bagian pendaftraran dalam melakukan tugasnya di unit rekam medis Rumah Sakit Umum Haji Medan.

2. Standar beban kerja adalah waktu kerja yang tersedia bagi tenaga rekam medis di bagian pendaftaran Rumah Sakit Umum Haji Medan dibagi rata-rata waktu yang digunakan untuk menyelesaikan kegiatan pokok.

3. Standar kelonggaran adalah waktu yang digunakan untuk melaksanakan kegiatan lain yang tidak berhubungan langsung tetapi bermanfaat bagi tenaga rekam medis di bagian pendaftaran Rumah Sakit Umum Haji Medan.

4. Perhitungan jumlah kebutuhan tenaga adalah total kuantitas kegiatan pokok dibagi dengan standar beban kerja tenaga rekam medis di bagian pendaftaran Rumah Sakit Umum Haji Medan.

Pengumpulan data primer melalui wawancara dan observasi serta menghitung waktu tunggu pasien di bagian pendaftaran. Data sekunder yaitu data mengenai jumlah kunjungan pasien rawat jalan dan rawat inap, SOP pendaftaran, Struktur organisasi, dan Kalender Rumah Sakit. Instrumen yang digunakan untuk melakukan penelitian ini adalah : Stop Watch , Tabel pengukuran, Pedoman Wawancara dan Pedoman Observasi. Analisa data untuk mendapatkan gambaran kebutuhan tenaga rekam medis di bagian 
pendaftaran Rumah Sakit Umum Haji Medan dengan menggunakan metode Workload Indicator of Staffing Need (WISN).

\section{HASIL}

Perencanaan Kebutuhan SDM Rekam Medis Berdasarkan Beban Kerja di Rumah Sakit Haji Medan

\section{Menetapkan Waktu Kerja Tersedia}

Diperoleh dari kerja efektif selama kurun waktu 1 tahun untuk masingmasing kategori SDM yang bekerja di Unit Rekam Medis Rumah Sakit HajiMedan. Data yang di dapat sebagai berikut :

Tabel 1. Waktu Kerja Tersedia

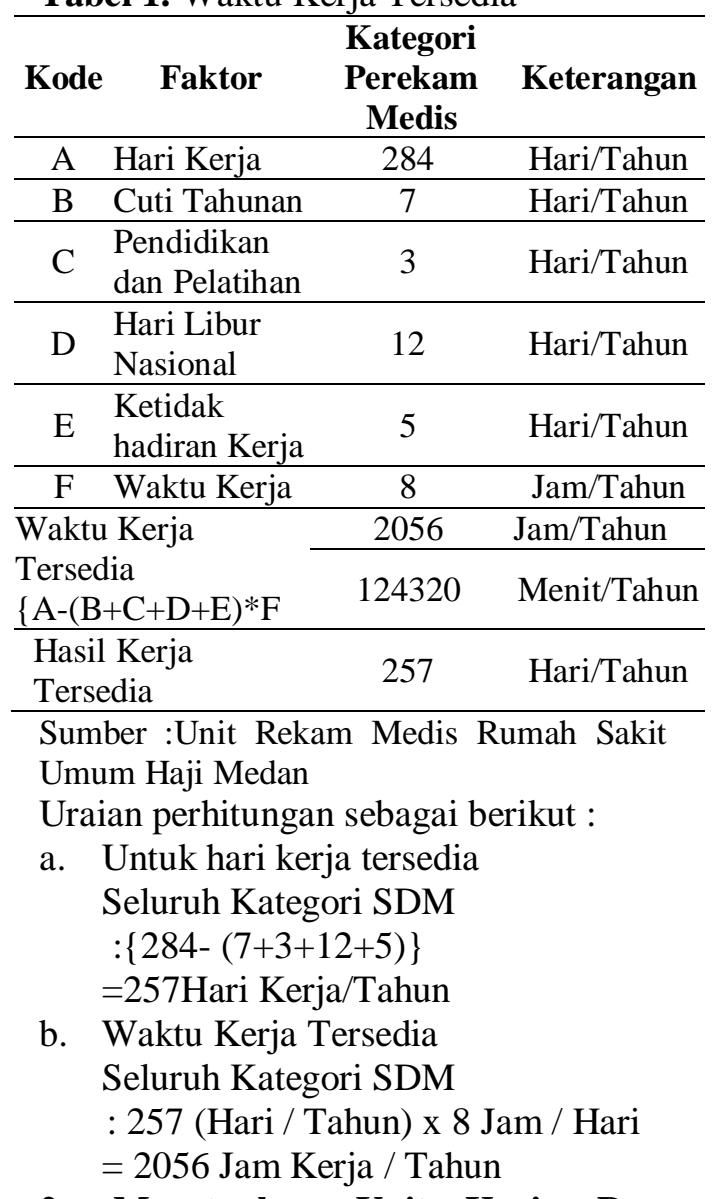

2. Menetapkan Unit Kerja Dan Ketegori SDM
Berdasarkan struktur organisasi bagian rekam medis Rumah Sakit Umum Haji Medan, membuat perencanaan unit kerja dan kategori bagian rekam medis yaitu petugas bagian unit rekammedis berjumlah 2 orang.

3. Menyusun standar beban kerja

Standar Beban Kerja yang ada di Rumah Sakit Umum Haji Medan di peroleh berdasarkan hasil perencanaan yang dilakukan oleh pihak rumah sakit, karena sistem yang digunakan sudah komputerisasi maka disesuaikan dengan kegiatan yang dilakukan pada saat ini, Standar Beban Kerja yang ada adalah sebagai berikut :

Menghitung Standar Beban Kerja di Rumah Sakit Umum Haji Medan Perhitungan sebagai berikut :

Dik : a. Waktu Kerja Tersedia = 124320 Menit/Tahun

b. Rata-Rata Waktu

$$
=5.5 \text { Menit=2.5 Menit }
$$

Dit : Standar Beban Kerja ?

Jawab : Standar Beban Kerja

$$
\begin{aligned}
& \text { Rawat jalan } \\
& =\text { Waktu Kerja Tersedia } \\
& \text { Rata-rata Waktu } \\
& =\frac{124320}{5.5} \\
& =22604 \\
& \text { Rawat inap } \\
& =\text { Waktu Kerja Tersedia } \\
& \text { Rata-rata Wa ktu } \\
& =\underline{124320} \\
& 2.5 \\
& =49728
\end{aligned}
$$

4. Menyusunan Standar Kelonggaran Standar kelonggaran yang ada di Rumah Sakit Haji Medan di sesuaikan dengan kegiatan-kegiatan yang ada dan dilakukan oleh masingmasing unit kerja, khususnya untuk unit kerja rekam medis dan seluruh sub unit rekam medis memiliki standar kelonggaran adalah sebagai berikut : 
Tabel 2. Standar Waktu Kelonggaran

\begin{tabular}{lccccc}
\hline Nama Kegiatan & $\begin{array}{c}\text { F } \\
\text { (Tahun) }\end{array}$ & $\begin{array}{c}\text { Jam } \\
\text { (waktu) }\end{array}$ & $\begin{array}{c}\text { Jumlah } \\
\text { (menit) }\end{array}$ & $\begin{array}{c}\text { Waktu Kerja } \\
\text { Tersedia }\end{array}$ & SKI \\
\hline $\begin{array}{l}\text { Kegiatan } \\
\text { Perhimpunan }\end{array}$ & 12 & 120 & 1440 & 124320 & 0.012 \\
\hline Narasumber & 2 & 120 & 240 & 124320 & 0.002 \\
\hline Rapat BPJS & 12 & 60 & 720 & 124320 & 0.002 \\
\hline Rapat Rutin & 12 & 60 & 720 & 124320 & 0.002 \\
\hline $\begin{array}{l}\text { Pelatihan } \\
\text { Rekam Medis }\end{array}$ & 3 & 120 & 360 & 124320 & 0.045 \\
\hline Seminar & 2 & 630 & 1260 & 124320 & 0.01 \\
\hline $\begin{array}{l}\text { Laporan Sesuai } \\
\text { Permintaan }\end{array}$ & 20 & 60 & 1200 & 124320 & 0.01 \\
\hline Adm BPJS & 255 & 60 & 15300 & 124320 & 0.123 \\
\hline Pelatihan Lain & 2 & 220 & 440 & 124320 & 0.007 \\
\hline Sumber : Unit Rekam
\end{tabular}

Sumber : Unit Rekam Medis Rumah Sakit Umum Haji Medan

Untuk perhitungannya sebagai berikut :

Dik : Rata-rata waktu (jam) $=161$ jam/tahun (Kegiatan Perhitungan) Waktu Kerja Tersedia $=2056$

Dit : Standar Kelonggaran?

Jwb: Standar Kelonggaran = Rata Rata Waktu

Waktu Kerja Tersedia $=\frac{161}{2056}=0.078$

\section{Kebutuhan Tenaga Per Unit Kerja}

Dalam perhitungan kebutuhan SDM dibutuhkan sumber data yang diperoleh dari langkah-langkah sebelumnya dan kuantitas kegiatan pokok tiap unit kerja selama kurun waktu satu data-data yang diperoleh dari langkah-langkah sebelumnya seperti data kegiatan pelayanan rawat jalan, rawar inap, standar beban kerja, standar kelonggaran merupakan data untuk perhitungan kebutuhan SDM di setiap unit kerja atau sub unit kerja penyimpanan rekam medis.Sumber data yang diperlukan untuk menghitung SDM per unit kerja salah satunya adalah Kuantitas Kegiatan Pokok yang dilakukan di unit rekam medis adalah sebagai berikut :

a. Kuantitas Kegiatan Pokok Rumah Sakit Haji Medan

Tabel 3. Kuantitas Kegiatan Pokok

\begin{tabular}{cccc}
\hline No & $\begin{array}{c}\text { Kategori } \\
\text { SDM }\end{array}$ & $\begin{array}{c}\text { Kegiatan } \\
\text { Pokok }\end{array}$ & Frekuensi \\
\hline \multirow{2}{*}{1} & $\begin{array}{c}\text { Perekam } \\
\text { Medis }\end{array}$ & $\begin{array}{c}\text { Rawat } \\
\text { jalan }\end{array}$ & 27583 \\
\cline { 3 - 4 } & Rawat inap & 6345 \\
\hline \multicolumn{2}{c}{$\begin{array}{c}\text { Hasil Kerja } \\
\text { Tersedia }\end{array}$} & 257 & $\begin{array}{c}\text { Hari/Tahu } \\
\text { n }\end{array}$ \\
\hline
\end{tabular}

Sumber :Unit Rekam Medis Rumah Sakit Umum Haji Medan

Tabel 4. Kebutuhan Sumber Daya Manusia

\begin{tabular}{llcccc}
\hline \multirow{2}{*}{ No } & $\begin{array}{c}\text { Kategori } \\
\text { SDM }\end{array}$ & $\begin{array}{c}\text { Kegiatan } \\
\text { Pokok }\end{array}$ & $\begin{array}{c}\text { Kuantitas } \\
\text { Kegiatan }\end{array}$ & $\begin{array}{c}\text { Standar Beban } \\
\text { Kerja }\end{array}$ & $\begin{array}{c}\text { Kebutuhan } \\
\text { SDM }\end{array}$ \\
\hline \multirow{2}{*}{1} & $\begin{array}{l}\text { Perekam } \\
\text { Medis }\end{array}$ & Rawat Jalan & 27583 & 22064 & 1.25 \\
\cline { 2 - 5 } & Rawat Inap & 6345 & 49728 & 0.13 \\
\hline \multicolumn{2}{l}{ Sub Total Kebutuhan SDM } & & & 1.38 \\
\hline \multicolumn{2}{l}{ Standar Kelonggaran } \\
\hline \multicolumn{2}{l}{ Total Kebutuhan SDM } \\
\hline
\end{tabular}

Sumber :Unit Rekam Medis Rumah Sakit Haji Medan

Berdasarkan rumus yang sudah di tentukan diatas kebutuhan SDM untuk tiap kegiatan pokok terlebih dahulu jumlahkan sebelum ditambahkan dengan standar kelonggaran yang ada di unit 
rekam medis, dan untuk proses perhitungannya :

Kebutuhan SDM petugas rekam medis

Sub Total Kebutuhan SDM

$=$ Kuantitas Kegiatan

Standar Beban Kerja

$=\underline{27583}$

22604

$=1.25$

$=\underline{\text { Kuantitas Kegiatan }}$

Standar Beban Kerja

$=6345$

49728

$=0.13$

Jadi sub total kebutuhan SDM adalah

$=1.25+0.13=1.38$

Standar Kelonggaran $=0.078$

Jadi, Total Kebutuhan SDM $=1.38+$ $0.078=1.428$

$$
=1 \text { orang }
$$

Jadi jumlah keseluruhan SDM yang dibutuhkan di unit rekam medis adalah 1 orang.

Upaya Penyelesaian Masalah yang Dilakukan oleh Unit Rekam Medis di Rumah Sakit Haji Medan

Upaya yang dilakukan oleh unit rekam medis Rumah Sakit Umum Haji Medan dalam menyelesaikan masalah yang timbul adalah :

1. Meminta tambahan petugas pada pimpinan dengan standar beban kerja yang di alami petugas.

2. Menambah ilmu pengetahuan agar semakin lebih baik dengan cara pelatihan dan seminar ataupun pendidikan formal.

\section{PEMBAHASAN}

Berdasarkan hasil perhitungan jumlah minimal kebutuhan tenaga rekam medis di bagian pendaftaran Rumah Sakit Umum Haji Medan, dengan jumlah pasien pada tahun 2017 untuk rawat jalan sebanyak 60364 hari/tahun. Maka tenaga rekam medis yang dibutuhkan saat ini untuk melakukan seluruh kegiatan yang ada di bagian pendaftaran adalah 6 orang, akan tetapi jumlah petugas di bagian pendaftaran saat ini sebanyak 5 orang.

Dari hasil perhitungan tersebut petugas pendaftaran di Rumah Sakit Umum Haji Medan harus menambahkan tenaga rekam medis sebanyak 1 orang agar bisa menjalankan pekerjaannya sesuai dengan PMK No.55 tahun 2013. Agar penyelenggaraan rekam Medis di Rumah Sakit Umum Haji lebih baik lagi sehingga beban kerja yang ada dapat cepat teratasi.

Sesuai dengan penelitian dilakukan Rahmawati (2015), menjelaskan petugas di unit rekam medis Rumah Sakit Assalam Gemolong sampai dengan bulan agustus 2015 sebanyak 8 orang. Sedangkan dari hasil perhitungan kebutuhan tenaga kerja unit rekam medis sebanyak 8,56 atau 9 orang. Sehingga kebutuhan tenaga rekam medis tahun 2015 memerlukan penambahan 1 orang tenaga di bagian pendaftaran karena di bagian pendaftaran masih terdapat rangkap pekerjaa atau dikerjakan oleh petugas pendaftaran dan petugas assembling, coding dan indexing, untuk mencapai produktifitas kerja yang optimal perlu adaya pendayagunaan dan pembagian tugas sesuai dengan job description

\section{KESIMPULAN}

1. Analisis kebutuhan Tenaga berdasarkan beban kerja di unit rekam medis di Rumah Sakit Haji Medan Tahun 2018 dengan menggunakan metode WISN (Workload Indicator Of Staffing Needing), jumlah SDM bagian pendaftaran adalah 2 orang, dan jumlah yang dibutuhkan adalah 1(satu) orang.

2. Pihak Rumah Sakit Umum Haji Medan dan Kepala Instalasi Rekam Medis melakukan kebijakan bahwa syarat kualifikasi petugas rekam medis atau telah mengikuti 
pendidikan dan pelatihan dasar serta mampu mengoperasikan komputer.

\section{DAFTAR PUSTAKA}

Aditama. (2010). Manajemen Administrasi Rumah Sakit. Jakarta: Universitas Indonesia

Alamsyah, D. (2012). Manajemen Pelayanan Kesehatan. Yogjakarta: Nuha Medika

Arsil R, dkk. (2006). Manual Rekam Medis. Jakarta: Konsil Kedokteran Indonesia.

Azwar, A. (2010). Pengantar Administrasi Kebijakan Kesehatan. Edisi ke-3. Jakarta: Binarupa Aksara.

Budi, S. (2011). Manajemen Unit Kerja Rekam Medis. Yogyakarta: Quantum Sinergi Media.

Bustami. (2011). Penjaminan Mutu Pelayanan Kesehatan dan Akseptabilitasnya. Jakarta: Erlangga.

Depkes RI. (2004). Peraturan Menteri Kesehatan Republik Indonesia Nomor 81/MENKES/SK/I/2004. Pedoman Penyusunan Perencanaan SDM Kesehatan di Tingkat Propinsi, Kabupaten/Kota serta Rumah Sakit. Jakarta: DEPKES RI.

Depkes RI. (2008). Petunjuk Pelaksanaan Penyelenggaraan Rekam Medis. Jakarta: DEPKES RI.

Depnaker, UU No. 14 tahun 1969. Ketentuan-Ketentuan Pokok TenagaKerja. Jakarta: Depnaker.

Direktorat Jendral Bina Pelayanan Medik. (2006). Pedoman Penyelenggaraan dan Prosedur Rekam Medis Rumah Sakit di Indonesia Revisi 2. Jakarta: Departemen Kesehatan RI.

Direktorat Jendral Bina Pelayanan Medik. (2008). Pedoman Pengelolaan Rekam Medis Rumah
Sakit di Indonesia. Jakarta: Departemen Kesehatan RI.

Edwin B. F, Personel Management, Mc. Grow - Hill, Inc, (Singapore, 1980) hlm. 5.

Gibony, Principles of Hospital Administration, dalam karangan Wirawan, Buletin Medical Record No.3 (Jakarta : PPSPM, 1983) hlm. 25.

Giyana F. (2012). Analisis Sistem Pengelolaan Rekam Medis Rawat Inap Rumah Sakit Umum Daerah Kota Semarang.

Hatta, G. (2011). Pedoman Manajemen Informasi Kesehatan di Sarana Pelayanan Kesehatan. Jakarta: UIPress.

Hariandja MTE.( 2007). Manajemen Sumber Daya Manusia: Pengadaan, Pengembangan, Pengkompensasian, dan Peningkatan Produktivitas Pegawai. Jakarta: Grasindo.

Hidayat, S, 2011. Metodologi Penelitian. Bandung : Mandar Maju.

Huffman, EK. (1994). Health Information Management, Edisi 10 (Illnois : PRF, 1994) hlm. 28.

Kemenkes RI. (2004). Peraturan Menteri Kesehatan Republik Indonesia Nomor 56 tahun 2014 tentang Klasifikasi dan Perizinan Rumah sakit. Jakarta: Kemenkes RI.

Kemenkes RI. 2008. Peraturan Menteri Kesehatan Republik Indonesia Nomor 269/MENKES/PER/III/2008

Tentang Rekam Medis. Jakarta: Kemenkes RI.

Kemenkes RI. (2013). Peraturan Menteri Kesehatan RI Nomor 55 Tahun 2013 Tentang Penyelenggaraan Pekerjaan Rekam Medis. Jakarta: Kemenkes RI.

Menpan RI. (2013). Peraturan Menteri Pendayagunaan Aparatur Negara dan Reformasi birokrasi Nomor 30 tentang jabatan fungsional perekam 
medis dan angka Kreditnya. Jakarta: Menpan RI.

Muthomimah I, dkk. (2015). Analisis Kebutuhan Tenaga Kerja Berdasarkan Beban Kerja Unit Rekam Medis Rumah Sakit Islam Kendal Tahun 201.

Nuraini N. (2010). Analisis Kebutuhan Tenaga Kerja Berdasarkan Beban Kerja Work Load Indicator Staff Atau WISN ( dalam jurnal Rekam Medis Vo.4 No.1). Karanganyar: APIKES Mitra Husada.

Notoatmodjo S. (2012). Metodologi Penelitian Kesehatan. Jakarta: Rineka Cipta.

Rustiyanto, Ery. (2009). Etika Perekam Medis dan Sistem Informasi Kesehatan. Yogyakarta: Graha Ilmu.

Siswati S. (2013). Etika dan Hukum Kesehatan dalam Perspektif Undang-Undang Kesehatan. Jakarta: Raja Grafindo Persada.

Sondang. (2010). Manajemen Sumber Daya Manusia, Edisi 1, Cetakan IV . Jakarta: Bumi Aksara.

Suma'mur. (2012). Hygine Perusahaan dan Keselamatan Kerja. Jakarta: Haji Massagung.

Sugiyono. (2010). Memahami Penelitian Kualitatif. Bandung: Alfabeta.
Sugiyono. (2011). Metode Penelitian Administrasi. Bandung: Alfabeta.

Suharyanto H., Agus H., 2005. Manajemen Sumber Daya Manusia. Yogyakarta: Media Wawancara.

Sulistyaningsih. (2011). Metodologi Penelitian Kebidanan: KuantitatifKualitatif. Yogyakarta: Graha Ilmu.

Tiffany, Dwi, Lanang. (2016). Tinjauan Beban Kerja Petugas Rekam Medis Guna Meningkatakan Produktivitas Petugas Unit Rekam Medis Rawat Jalan di Rumah Sakit. Dustira Cimah. 61-76.

Terry G R. (2011). Dasar-Dasar Manajemen Cetakan Kesebelas. Jakarta: PT. Bumi Aksara.

Undang-undang Republik Indonesia. (2003). Nomor 13 Tahun 2003 tentang Ketenaga Kerjaan, Jakarta. Undang-undang Republik Indonesia.

Undang-undang Republik Indonesia. (2009). Nomor 44 Tahun 2009 Tentang Rumah Sakit. Jakarta. Undang-undang Republik Indonesia.

Undang-undang Republik Indonesia. (2004). Nomor 29 Tahun 2004 Tentang Praktik Kedokteran. Jakarta: Undang-undang Republik Indonesia. 